\title{
Early ambulation versus immobilization in the management of patients with distal deep venous thrombosis
}

\author{
Ayman Omar,MD; Hisham Abu Greda, MD Vascular \\ Surgical Unit, Department of General Surgery, \\ Menoufiya University Hospitals, Shebin El-Kom, Egypt.
}

\begin{abstract}
Background: The encouragement of early ambulation with compression rather than bed-rest becomes a matter of controversy.

Aim: To evaluate the benefits of compression and walking exercises in comparison with bed rest in the acute stage of distal deep venous thrombosis.

Methods: Twenty-eight patients with distal DVT that were randomized into 2 groups. The first group: 14 patients received low-molecular-weight heparin (LMWH) associated with bed rest \& leg elevation for 7-10 days. The second group: 14 patients received LMWH and were allowed to be ambulant after 1-2 days with elastic compression stocks. Patients $\cdot$ assessment was essentially concerning with the reduction of leg pain \& swelling and also checking out the propagation of thrombosis and/or development of pulmonary embolism.

Results: Leg pain was reduced or abolished in 12/14 patients in the ambulant group compared to 10/14 patients in the bed-rest group. Also; the reduction of limb swelling in the ambulant group was better than that of the bed-rest one.Furthermore; propagation of thrombus was more in the bed-rest group (2/14) compared to the ambulant one (1/14).

Conclusion: Patients with acute distal DVT treated with LMWH should be encouraged to walk with medical compression stockings.
\end{abstract}

Keywords: Deep vein thrombosis, ambulation, pulmonary embolism.

\section{Introduction:}

Acute DVT still has a bad reputation both in the eye of the patients and in the mind of medical professionals because of serious leg problems, pulmonary embolism and death. Confinement to bed and complete immobilization appeared as logical treatment option and was never challenged. Nowadays, with rapid anticoagulant treatment the risk of symptomatic recurrence of thrombosis and pulmonary embolism has been virtually decreased, but the optimal treatment of the signs and symptoms is still ignored. Also; there are an increasing number of patients with DVT that treated entirely on the out-patient basis.1,2,3

Several prospective studies did not show any increased danger of pulmonary embolism if mobile patients are treated with LMWH and keep walking with compression bandages regardless of the size or location of the thrombi.4, 5 Furthermore; many authors had postulated that patients with DVT recover much faster when they are encouraged to walk with finn compression bandage.1,6,7,8 However; until now, evidence-based data proving the advantages of active walking exercises with compression is lacking.

Aim of the work:

The aim of the present study is to evaluate the value of early ambulation and compression versus the current standard of bed rest in association with heparinization with LMWH in patients with distal deep vein thrombosis in a sample of Egyptian patients.

\section{Patients and methods:}

This prospective study was carried out at Menoufyia University Hospitals. Patients with popliteal or calf acute DVT and fitting the inclusion criteria of the study were included. Patients, recruitment started from January 2009 till January 2010. The diagnosis ofDVT was essentially based on duplex scanning. 
Inclusion criteria:

Patients 18 years with their first episode of acute distal DVT (popiteal and/or calf).

\section{Exclusion criteria:}

Patients with symptomatic pulmonary embolism as chest pain and dyspnea, patients with concomitant arterial diseases, recurrent DVT, proximal DVT, cancer patients, patients with recent surgery, orthopedic patients, pregnant females, sever hypertension (systolic $>200 \mathrm{~mm} \mathrm{Hg}$ or diastolic $>100 \mathrm{~mm} \mathrm{Hg}$ ), atrial fibrillation or known right to left shunt.

Patients were randomized into 2 groups. The first group: Patients received lowmolecular-weight heparin (LMWH) associated with bed rest \& leg elevation for 7-10 days. The second group: Patients received LMWH and were allowed to be ambulant after 1-2 days.

Low-molecular-weight heparin given to all patients in both groups was Enoxaparin in a dose of $1 \mathrm{mg} / \mathrm{kg} / \mathrm{SC} / 12 \mathrm{hrs}$. Also; all patients have warned below knee class II elastic compression stocks at the proposed time. Patients' assessment:

All patients in both groups were evaluated in respect to:

- Improvement of associated clinical features (pain, swelling, .. ect).

- Propagation of thrombosis and/or - Development of pulmonary embolism.

Patients showed suspicious of pulmonary embolization (chest pain or dyspnea) during the first 10 days of their treatment underwent necessary screening tests for pulmonary embolism. These included; arterial blood gases, ECG changes of right heart strain classically S1Q3T3 \& spiral CT chest whenever necessary.

\section{Randomization:}

Protocol-eligible patients were prospectively randomized according to a computer-generated code, based on the order of their admission to the study. Each patient was assigned to ambulant or bed-ridden group. When the patient agreed to take part in the study, he or she opened a sealed opaque envelop holding the number that correlates with his/her tum of admittance to the study. Therefore, once the envelope has been opened, the investigator knows the treatment strategy that would be applied.

\section{Statistical analysis:}

The usefulness of ambulation in reducing the limb circumference and in alleviating the patients' symptoms was analyzed by the t-test for two samples with unequal variance (confidence level 95.0\%). where data were normally distributed and expressed by their mean \pm standard error of mean (SEM). Differences were considered significant if the $\mathrm{P}$ value was 0.05 or lower. In this study; the analysis of data was carried out using the Minitab 13.1 Statistical Package (Mini tab Inc, Pennsylvania, USA).

\section{Results:}

Patient demography:

Twenty-eight patients participated in the study (14 patients in each group). The age difference in both groups was not statistically significant $(53.6 \pm 15.22$ versus $56.92 \pm 14.87$; $\mathrm{P}=0.4$ ). Also; the males participated in both groups were more than females, however; the difference was not significant $(55 \%$ vs $40 \%$; $\mathrm{P}=0.3)$. Patients' demography is shown in Table(1).

Table (1): Patient's demography.

\begin{tabular}{|l|c|c|}
\hline & $\begin{array}{c}\text { Bed-rest group } \\
\mathrm{n}=14\end{array}$ & $\begin{array}{c}\text { Ambulant group } \\
\mathrm{n}=14\end{array}$ \\
\hline Patient age (years) & $53.6 \pm 15.22$ & $56.92 \pm 14.87$ \\
\hline ( F /M) ratio & $5 / 9(55 \%)$ & $4 / 10 \quad(40 \%)$ \\
\hline DVT Rt Limb & 10 & 8 \\
Lt Limb & 4 & 6 \\
Rt + Lt & 0 & 0 \\
\hline
\end{tabular}


Clinical features associated with DVT at patients' first presentation:

Pain was the common presenting feature among all patients in both groups. However; leg swelling was a common feature also, presented in $64.3 \%$ \& $85.7 \%$ in the bed-rest and ambulant groups respectively. Also; local limb warmth was an associated common feature, presented in $64.3 \%$ \& $78.6 \%$ in the bed-rest and ambulant groups respectively. This is shown in Table(2).

Table (2): Clinical features associated with DVT at patients' first presentlltion.

\begin{tabular}{|l|c|c|}
\hline & $\begin{array}{c}\text { Bed-rest group } \\
\mathrm{n}=14\end{array}$ & $\begin{array}{c}\text { Ambulant group } \\
\mathrm{n}=14\end{array}$ \\
\hline Pain & $14 / 14(100 \%)$ & $14 / 14(100 \%)$ \\
\hline Swelling & $9 / 14(64.3 \%)$ & $12 / 14(85.7 \%)$ \\
\hline t Leg temperature & $9 / 14(64.3 \%)$ & $11 / 14(78.6 \%)$ \\
\hline
\end{tabular}

Clinical features associated with DVT after one week:

Improvement of clinical features in both groups was a common finding. Limb swelling subsided in 6/9 (66.6\%) in the bed-rest group versus $11112(91.6 \%)$ in the ambulant group. This difference in improvement among both groups was statistically significant $(95 \%$ $\mathrm{CI}=23.3-92.7$, Chi Square $=5.353 ; \mathrm{P}=0.02)$. This is shown in Table(3).

Table (3): Clinical features associated with DVT after one week.

\begin{tabular}{|c|c|c|}
\hline & $\begin{array}{c}\text { Bed-rest group } \\
\mathrm{n}=14\end{array}$ & $\begin{array}{c}\text { Ambulant group } \\
\mathrm{n}=14\end{array}$ \\
\hline Pain & $4 / 14 \quad(28.6 \%)$ & $2 / 14(14.3 \%)$ \\
\hline Swelling & $3 / 14 \quad(21.4 \%)$ & $1114(7.1 \%)$ \\
\hline Leg temperature & 0 & 0 \\
\hline
\end{tabular}

Differences in limb girth at patients' first presentation:

There were little differences in the circumferences (ankle/ mid-leg/ mid-thigh) between the affected limb \& the sound limb in both groups. The differences in circumferences in the bed-rest group were $(1.47 \pm 1.03,2.67 \pm 1.50 \& 1.13 \pm 1.22)$ versus $(1.93 \pm 1.53,2.93 \pm 1.45 \& 1.06 \pm 1.47)$ in the ambulant group. However; such differences between both groups was not significant. This is shown in Table(4).

Table (4): Differences in limb girth atpatients' first presentation.

\begin{tabular}{|c|c|c|}
\hline & $\begin{array}{c}\text { Bed-rest group } \\
\mathrm{n}=14\end{array}$ & $\begin{array}{c}\text { Ambulant group } \\
\mathrm{n}=14\end{array}$ \\
\hline Ankle & $1.47 \pm 1.03$ & $1.93 \pm 1.53$ \\
\hline Mid-calf & $2.67 \pm 1.50$ & $2.93 \pm 1.45$ \\
\hline Mid-thigh & $1.13 \pm 1.22$ & $1.06 \pm 1.47$ \\
\hline
\end{tabular}


Differences in limb girth after one week:

After one week of treatment, both groups of patients showed reduction in their limb swelling compared to the sound limb. The differences in the limb circumferences in the bed-rest group were $\{1.2 \pm 1.28,1.40 \pm 1.53$ and $1.07 \pm 1.31 \mathrm{em}$ ) and inthe ambulant group $\{1.30 \pm 0.80,1.90 \pm 1.28$ and $1.09 \pm 1.30 \mathrm{em})$. However; such differences between both groups were not significant. This is shown in Table(5).

Table (5): Differences in limb girth after one week.

\begin{tabular}{|c|c|c|c|}
\hline & $\begin{array}{c}\text { Bed-rest group } \\
\mathrm{n}=14\end{array}$ & $\begin{array}{c}\text { Ambulant group } \\
\mathrm{n}=14\end{array}$ & $\begin{array}{c}\text { P-value } \\
\text { student t-test }\end{array}$ \\
\hline Ankle & $1.20 \pm 1.28$ & $1.30 \pm 0.80$ & $\mathrm{P}=0.6$ \\
\hline Mid-calf & $1.40 \pm 1.53$ & $1.90 \pm 1.28$ & $\mathrm{P}=0.3$ \\
\hline Mid-thigh & $1.07 \pm 1.31$ & $1.09 \pm 1.30$ & $\mathrm{P}=0.4$ \\
\hline
\end{tabular}

Duplex findings at patients' first presentation:

Vein thrombosis at patients' first presentation was located to the calf veins in 5 patients in the bed-rest group versus 8 patients in the ambulant group. Also; involvement of the popliteal vein was detected in 3 patients in the bed-rest group versus 2 patients in the ambulant group. Furthermore; the combined calf and popliteal veins thrombosis was detected in 6 patients in the bed-rest group versus 4 patients in the ambulant group. The difference inallocation of venous thrombosis among both groups of patients was not significant. This is shown in Table(6).

Table (6): Duplex findings at patients' first presentation.

\begin{tabular}{|c|c|c|}
\hline & $\begin{array}{c}\text { Bed-rest group } \\
\mathrm{n}=14\end{array}$ & $\begin{array}{c}\text { Ambulant group } \\
\mathrm{n}=14\end{array}$ \\
\hline Calf veins & $5 / 14(35.7 \%)$ & $8 / 14(57.1 \%)$ \\
\hline Popliteal vein & $3 / 14(21.4 \%)$ & $2 / 14(14.3 \%)$ \\
\hline Calf veins+ popliteal vein & $6 / 14(42.9 \%)$ & $4 / 14(28.6 \%)$ \\
\hline
\end{tabular}

Duplex findings after one week:

Propagation of thrombosis appeared in the bed-rest group in 2 patients $2 / 14$ (14\%), and appeared in one patient in the ambulant group $1 / 14(7 \%)$. No clinical suspicioun of pulmonary embolism appeared in both groups of patients.

\section{Discussion:}

In the past few decades, patients with active DVT were placed on bed rest for periods up to 7-10 days due to the fear of PE among patients who remain active.9,10,11 Bed rest is recommended because of the concern of clot dislodgment by ambulation \& to decrease the limb pain \& edema. 12
Conversely; bed rest can be incriminated in promoting blood stasis and propagation of thrombosis with subsequent elongation of the hospital stay.13,14,15 Furthermore; more recent practice has included earlier ambulation, but there has been reluctance to begin ambulation immediately after diagnosis and initial management ofDVT.In practice, there appears to be no standard protocol for activity progression in the early days of treating DVT.16

World-wide; early ambulation is rarely recommended as part of the initial management of thrombo-embolic disorders. However; as soon as a level of effective anticoagulation has been reached, ambulation is allowed in many centers in the world.17 This approach is being opposed by other authors who believed that a 
new or progression of DVT was observed among patients managed with early ambulation.5,9

Home therapy for DVT is a running new era over the last couple of decades especially with the introduction ofLMWH. The rationale of home therapy of acute DVT is essentially based many factors:

- The new nature anticoagulation

- the encouragement of early ambulation \& -cutting the cost of hospital stay.

There is eligibility for home therapy. Anticoagulation is the main line of treatment ofDVT, as well as PE, consisting usually of LMWH, promptly followed by oral therapy.18

The study design in regards to the hypothesis, aim, methods \& results were incorporated in order to investigate the usefulness \& safety of early ambulation in patients with acute DVT compared to patients confined to bed rest for a proposed period. Although this particular area of research has been explored world-wide in limited centers, we did try to find out the natural history of this dilemma ina sample ofEgyptian patients $\{$ MidDelta territory).

This has been achieved by recruiting 28 patients (28 lower limbs) with acute deep venous thrombosis of calf veins and popliteal vein of the leg. The patients were randomized into two equal groups. The first group:patients were confined to bed rest \& leg elevation for 7-10 days. The second group: patients were allowed to be ambulant after 1-2 days. All patients in both groups received therapeutic heparinization with LMWH overlapped by oral anticoagulant and have warned below knee class Nelastic stocks.

\section{Patients demography:}

The two groups were comparable in regards to the age of patients $(53.6 \pm 15.22$ versus $56.92 \pm 14.87$ years respectively) and also in regards to their gender type ( 5 females in bedrest group \& $\mathbf{4}$ females in ambulant group). Females were infrequent than males in both groups. This difference was not statistically significant $(55 \%$ versus $40 \% ; \mathbf{P}=0.3)$. The impact of age \& patients' gender does not seem to have any impact on the progress or outcome of either treatment options. These came in agreement with that in literature.19
Limb pain \& swelling in both groups:

Pain and swelling of the leg with symptomatic DVT have considerable subjective relevance for the patient's quality oflife. Until now these parameters have been widely neglected in most studies concentrating on therapeutic outcomes. BUi.ttler and Partsch 20 have reported the usefulness of walking with compression on relieving pain \& edema in patients with acute DVT.

In the present study; leg pain associated with acute DVT was reduced or abolished in $12 / 14$ patients in the ambulant group compared to $10 / 14$ patients in the bed-rest group. However; this difference was not statistically significant $(\mathrm{P}<0.5)$. Furthermore; the reduction of leg swelling was achieved in all patients in both groups as mentioned earlier. The reduction of limb swelling in the ambulant group was better than that of the bed-rest one. However although the reduction in limb swelling was not significant $(\mathrm{P}<0.1)$, it was reflected on patients' comfort \& was appreciated. Our results came in agreement with that of previous studies of Partsch $\mathrm{H}$ in 20057 \& Nadia et ai.8 in2009.

\section{Propagation of thrombosis in both groups:}

In 2004; BHittler and Partsch4 did a randomized controlled trial on 53 patients with proximal DVT; comparing bed rest for 9 days without compression with walking exercises using compression stockings or bandages. All patients were treated with therapeutic doses of LMWH. Thrombus size was assessed by duplex examination on day 0 and 9. An increase in the length of the thrombus in the femoral vein was seen in $40 \%$ of individuals in the bed-rest group, and in $28 \%$ of those who were encouraged to walk with compression bandages or stockings. The difference was not statistically significant However; the thrombus size showed a statistically significantly greater enlargement in those patients confined to bed compared to ambulatory patients with compression therapy $(\mathrm{P}=0.01)$.

Also; the American Venous Forum,21 has reported that the progression of thrombi in the femoral vein was greater and occurred more frequently in patients encountered to bed rest during their anticoagulation therapy.8,22,23

In the present study and after one week of 
either treatment regimen; pulmonary embolism was not suspected clinically in any patients. However; serial duplex scanning did reveal that the propagation of thrombus was more in the bed-rest group $(2 / 14)$ compared to the ambulant one $(1 / 14)$ respectively; $\mathrm{P}=0.2$ ). The difference was not significant. Truthfully; we did not measure the propagation of thrombosis by centimeters, but we did investigate the involvement of more proximal vein segment. That is why we did not encounter with significant findings in thrombus propagation than that achieved in previous studies.

Our findings confirm those from previous reports suggesting that bed rest has no influence on the risk of developing pulmonary embolism among patients with acute DVT of the lower limbs. Furthermore; early ambulation has other beneficial effects by alleviating pain, improving the quality of life, and lowering the rate of postthrombotic syndrome. Since it may allow home treatment or early discharge from the hospital, it might be cost-effective.

\section{References:}

1- Partsch H, Kaulich H, Mayer W:Immediate mobilisation in acute vein thrombosis reduces post-thrombotic syndrome. Int Angiol2004; 23:206-212.

2- C Kearon JS, Ginsberg JA, Julian MM, et al: Fixed-Dose Heparin (FIDO) Investigators. Comparison of fixed-dose weight-adjusted un:fractionated heparin and low- molecular- weight heparin for acute treatment of venous thromboembolism. JAMA 2006; 296: 935-942.

3- Yusen RD, Haraden BM, Gage BF, et al: Criteria for outpatient management oflower extremity deep venous thrombosis. Chest 2007; 115:972-979.

4- Blattler W, Partsch H:Leg compression and ambulation is better than bed rest for the treatment of the symptoms of acute deep venous thrombosis. Int Angio/2004; 22: 393-400.

5- Arcelus 11, Cohen AT, Agnelli G, et al: Venous thromboembolism (VTE) in Europe. The number of VTE events and associated morbidity and mortality. Impact Assessment Group in Europe (VITAE). Thromb Haemost 2007; 98(4): 756-764.

6- Kovacs MJ, Rodger M, Anderson DR, et al: Comparison of 10-mg and 5-mg warfarin initiation nomograms together with lowmolecular-weight heparin for outpatient treatment of acute venous thromboembolism. A randomized, double-blind, controlled trial. Ann Intern Med 2003; 138(9): 714-719.

7- Partsch H: Immediate ambulation and leg compression in the treatment of deep vein thrombosis. Disease a Month 2005; 51: 135-140.

8- Nadia A, Edith M, Stephane M, et al: A meta-analysis of bed rest versus early ambulation in the management of pulmonary embolism, deep vein thrombosis, or both. International Journal of Cardiology 2009; 137: 37-44.

9- Arcelus JI, Caprini JA, Monreal M, et al: The management and outcome of acute venous thromboembolism: A prospective registry including 4011 patients. J Vase Surg 2003; 916-922.

10-Panis $\boldsymbol{U}$, Kolbach DN, Hamulyak K, Prins $\mathrm{MH}$ : Identifying inappropriate hospital stay in patients with venous thromboembolism. Eur J Intern Med 2004; 15: 39-44.

11-Messina LM, Tierney LM Jr: Thrombophlebitis of the deep veins. In: Current Medical Diagnosis and Treatment. Tierney LM Jr, McPhee SJ, Papadakis MA, (Editors); New York, NY: Lange Medical Books/McGraw-Hill (Publisher); 40th ed. 2001; p.493-495.

12-Huisman MV, Biiller HR, ten Cate JW, et al: Unexpected high prevalence of silent pu1monary embolism in patients with deep venous thrombosis. Chest 2007; 498-502.

13-Kiser TS, Stefan VA: Pulmonary embolism in rehabilitation patients: Relation to time before return to physical therapy after diagnosis of deep vein thrombosis. Arch 
Phys Med Rehabil 1997; 78: 942-945.

14-Geerts WH, Pineo GF, Heit JA, et al: Prevention of venous thromboembolism, Chest 2004; 126:338-400.

15-Villalta P, Bagatella D, Piccioli A, et al: Assessment of validity and reproducibility of a clinical scale for the post-thrombotic syndrome. Hemostasis 2005; 35: 158a.

16-Aldrich D, Hunt DP: When can the patient with deep venous thrombosis begin to ambulate? Phys Ther 2004; 84:268-273.

17-Koopman MMW, Prandoni P, Piovella F, et al: Treatment of venous thrombosis with intravenous unfractionated heparin administered in the hospital as compared with subcutaneous low-molecular-weight heparin administered at home. $N$ Engl $J$ Med 2008; 356: 682-687.

18-Kearon C, Kahn SR, Agnelli G, Goldhaber S, Raskob GE, Comerota AJ: Antithrombotic therapy for venous thromboembolic disease:American College of Chest Physicians. Evidence-Based Clinical Practice Guidelines (8th Edition). Chest 2008; 133(6): 454-545.
19-Partsch H, Winiger J, Lun B: Compression stockings reduce occupational leg swelling. Dermatol Surg 2004; 30(5): 737-743.

20-Blattler W, Partsch H: Leg compression and ambulation is better than bed rest for the treatment of the symptoms of acute deep venous thrombosis. Int Angiol2003; 22:393-400.

21-EklofB, Rutherford RB, Bergan JJ, et al: American Venous Forum International Ad Hoc Committee for Revision of the CEAP Classification. JVase Surg 2004; 40(6): 1248-1252.

22-Allen C, Glasziou P, Del MarC: Bed rest: A potentially harmful treatment needing more careful evaluation. Lancet 1999; 354: 1229-1233.

23-Trujillo-Santos J, Perea-Milla E, JimenezPuente A, Sanchez Cantalejo E, del Toro $\mathrm{J}$, Grau E, et al: Bed rest or ambulation in the initial treatment of patients with acute deep vein thrombosis or pulmonary embolism: Findings from the RIETE registry. Chest 2005; 127: 1631-1636. 